\title{
YALE'S BOYER CENTER FOR MOLECULAR MEDICINE
}

\author{
Vincent T. Marchesi, M.D., Ph.D., Director
}

A. N. Brady Professor, Pathology, Biology, and Cell Biology

The decision to create a center for molecular medicine at the Yale School of Medicine was made more than a decade ago by the then Dean Leon Rosenberg and a few senior faculty advisers. At that time, the promise of this approach was on the horizon but not yet within easy reach. At Yale, along with comparable academic medical centers throughout the country, human biology and the pathogenesis of disease had been studied using state-of-the-art approaches for decades, but, for many reasons, studying the underlying mechanisms of most complex disease processes was rarely possible. All this has been changed dramatically, largely within the last decade, by the imaginative application of molecular genetics and related molecular biological tools to study just about every imaginable human condition. The power of this technology has already exceeded even the most optimistic expectations.

After the decision was made to create a new center as part of the Yale School of Medicine, the Yale planners had the good fortune to join forces with the Howard Hughes Medical Institute (HHMI) at a time when HHMI was recruiting new staff to explore similar research themes. The two groups together planned the enterprise that is now the showpiece of the Yale Medical Center (Fig. 1).

The first priority of the planners of Yale's Boyer Center was to create a center to which new faculty, skilled in the arts of molecular biology, could be recruited to work on research questions that bore directly on some aspect of human medicine. To reinforce this goal, members of each research unit were recruited to join a specific program, as opposed to being recruited to a traditional academic department. One result of this "discipline-blind" recruitment was to assemble research groups composed of traditional biochemists, cell biologists, structural biologists, geneticists, experimental pathologists, and a significant number of clinical scientists. Probably the most distinctive feature of Yale's Boyer Center is the fact that each faculty member was chosen both for an orientation towards molecular medicine and shared interest in a specific research theme.

The four programs being pursued in the Boyer Center and the names of each program director are listed below:

\section{Molecular Genetics}

Director: Joan A. Steitz, Ph.D.

Henry Ford II Professor of Molecular Bio-

physics and Biochemistry

Investigator, Howard Hughes Medical

Institute

Molecular and Developmental Neurobiology Director: Spyridon Artavanis-Tsakonas, Ph.D. Professor of Cell Biology and Biology Investigator, Howard Hughes Medical Institute

Molecular Oncology and Development Director: Sherman Weissman, M.D. Sterling Professor of Genetics and Medicine

Molecular Cardiobiology

Director: Jordan S. Pober, M.D., Ph.D.

Professor of Pathology, Immunobiology and Biology

The "programmatic" character of the Boyer Center is worth emphasizing, since in many ways it represents an effective way to apply basic science technology to the study of complex diseases. By creating a program around a common theme, for example, cardiobiology, it has been possible to recruit and house together, within shouting distance of one another, investigators trained in cell biology, genetics, pharmacology, experimental pathology, and clinical cardiology. The value of this combined effort goes beyond the simple sharing of different technologies that often occurs among members of different medical school departments. In the usual collaboration between faculty housed in different departments, individuals with special technical skills are recruited to collaborate, in some specific way, on a project that is centered in either a clinical or basic science department, where the dominant 


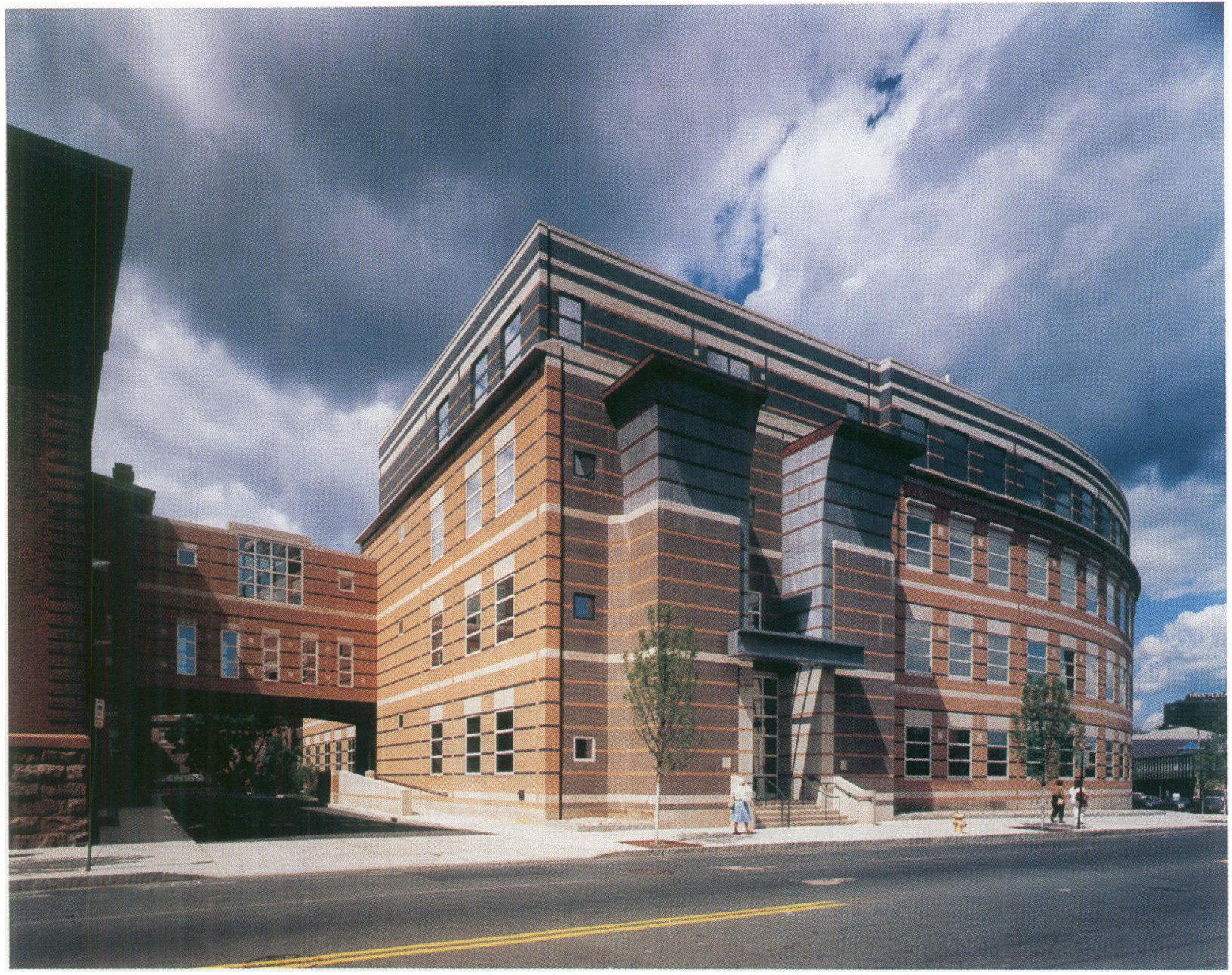

FIG. 1. Boyer Center for Molecular Medicine, New Haven, CT, U.S.A.

Photograph by Timothy Hursely

discipline drives the intellectual focus of the unit. In a center where the Program is the integrating factor, no one discipline is dominant, and, perhaps for that reason, the most useful features of a discipline are shared by the entire group. For the same reasons, seminars and journal clubs organized by members of programs focus more on questions relevant to the problem, as opposed to department-based meetings, where there may be a heavier emphasis on a core technology.

Programs that recruit a mixture of basic and clinical scientists to the study of a clinically related problem are able to mobilize more scientific firepower to join in the effort, than would be possible if only one academic department was involved. At Yale, and one assumes this to be true elsewhere, it has been particularly difficult for any one existing department to generate the resources needed to work on multifactorial disease processes, at the level required to make significant gains. In the case of research on dis- eases affecting the vascular system, to choose one example, the tools of molecular biology give us the chance to study the biology of the once inaccessible endothelial cell in ways that would astonish vascular biologists working in the decades before the development of recombinant DNA. The techniques of classical biochemistry were difficult to apply to the study of small blood vessels, since they could not be easily isolated in sufficient quantities for studying by conventional methods. But, now that we have the appropriate tools, the insights they provide into the workings of the microvasculature during inflammation give us the opportunity to design novel ways to modify the biology of microcirculation in a variety of diseases. Progress in using them to real advantage will only come when creative scientists of many stripes can work together under conditions that provide more than casual collaborations.

Centers of molecular medicine may help to satisfy this vital need. 